\title{
Discovering the Total Contents of the Universe
}

Ing Jeoraj Jain*

Tata Motors Ltd, Kamani Centre, Bistupur, Jamshedpur, India

\begin{abstract}
Modern scientists have been searching for clues of some type of extra-terrestrial life. However, ancient scriptures give very interesting and important information and details concerning the total contents of the whole universe. But it is given in a mathematical language, which has long been forgotten by the mankind. As such people have been interpreting those contents, as per their own limited knowledge of Geography and Cosmology.

This has naturally, brought about several contradictions and created serious mismatch with the latest scientific findings.

The author claims to have deciphered the Code, in which the Risis (Saints) had explained the contents of the universe (Lokākāŝa) in terms of living and non-living substances, along with its dependence on time-cycle.

It transpires that several puzzles, which remained hitherto as a myth, could easily be resolved by this ancient map. Even the latest scientific findings about the living and non-living matter of the cosmos can mostly be matched and fitted into the available ancient Lokākāŝa map.

Statistical data derived from the Lokākāŝa can provide invaluable guidance and right direction to the scientists in several fields for future explorations.

For example: It gives important information about the distribution of living and non-living substance of the universe.

The chart clearly exhibits the existence of human-civilizations on many planets, scattered in the universe. Some of them are spiritually more advanced than ours. Sub-human life form exists on innumerable planets in the universe

Apart from 7 states of matter and 7 phases of first 2 states of matter, (whose present knowledge is still at a very initial stage), the protean matter and protean-bodied life-form are still to be discovered by the scientists.

We still have very scanty knowledge about the Corona of Galaxies. The properties of the protean stuff, as given in the scriptures, may probably provide some clues to understand the dynamics of this invisible matter of Corona.
\end{abstract}

Keywords: Contents of Universe; Geographical maps; Lokākāŝapictographs; Gross and Protean bodies; States and phases of non-living matter; Statistical collective representation; Types of livingbeings

\section{Level of Our Knowledge}

\section{Geography of earth}

Our spherical earth is a planet, circling around the Sun (Figure 1). It has horizontal islands of Eurasia etc., and vertical islands of Africa and Americas from north to south [1].

The coastal areas of continents are unsymmetrical and zigzag Figure1 in shape. At places land-mass protrudes into water-mass or water-mass protrudes into land-mass. One rotation of earth on its axis takes 24 hours. The diameter of earth is about $13,000 \mathrm{~km}$. Three fourth area of its surface is covered by oceans like Pacific, Atlantic and Indian Ocean etc.

\section{Present cosmology}

The earth, mars etc. are the 9 planets of our Sun. Our Sun is located at the outer fringes of the half arm of our galaxy named as Lokākâŝa (Figure 2). There are more than 1000 billion such stars, as Sun, found in our galaxy $[2,3]$. Our Galaxy consists of a flat sub-system, called Disk and the spherical sub-system, within which the disk is located. The disk contains interstellar gas, cosmic dust and stars. The spherical sub-system does not contain any gas and dust, but only stars or clusters of stars. The stars of the disk revolve around its center at much faster speed than the stars of the spherical sub-system Most of the stars of the disk are binaries.

Galaxy's nucleus is a source of intense radio, infra, X-rays \& gamma-rays emissions. The mass of the galaxy is equal to about 1000 billion Suns $(2 \times 1044 \mathrm{~g})$. The Galaxy is surrounded by an external Corona, stretching dozens of times farther from the center than the disk and spherical sub-system. The total mass of the Corona is several times that of all the galaxy's stars put together. But because of large dimensions, the corona's density is much smaller than that created by stars and gas dust clouds. It does not emit any light and there are neither stars nor clouds in it. It makes itself felt by its gravitation.

In this Universe (Lokākāŝa) there are more than 100 billion galaxies. The life of the universe is estimated at 13.4 billion light years. As per one theory, the universe is not in a dynamic steady state, but is expanding at a great acceleration. Scientists also claim that the visible

*Corresponding author: Ing Jeoraj Jain, Tata Motors Ltd, Kamani Centre, Bistupur, Jamshedpur-831001, India, Tel: +9194313 01905; E-mail: dr.jeorajjain.38@gmail.com

Received January 14, 2014; Accepted February 17, 2014; Published February 24, 2014

Citation: Jain IJ (2014) Discovering the Total Contents of the Universe. J Astrophys Aerospace Technol 2: 102. doi:10.4172/2329-6542.1000102

Copyright: (c 2014 Jain IJ. This is an open-access article distributed under the terms of the Creative Commons Attribution License, which permits unrestricted use, distribution, and reproduction in any medium, provided the original author and source are credited. 

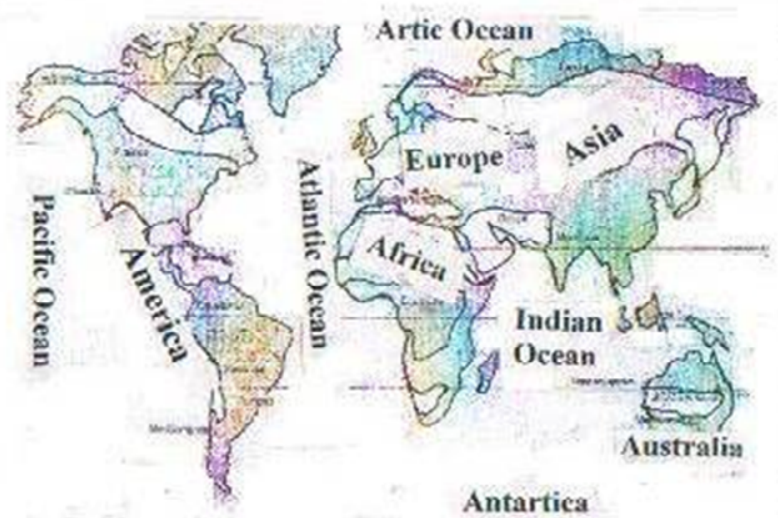

Antartica

Figure 1: A Geographical Map of our Earth.

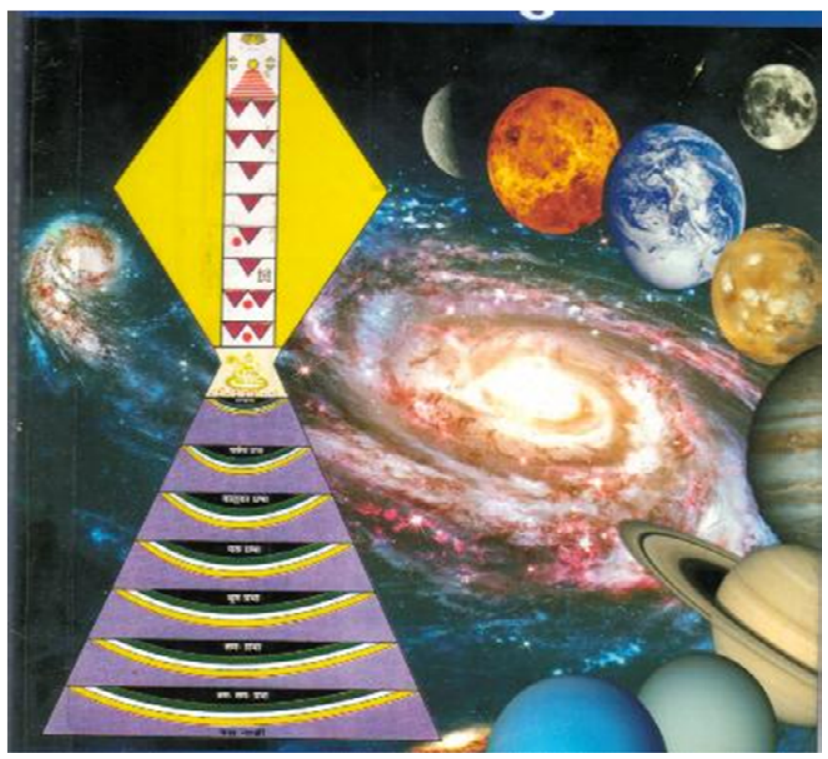

Figure 2: Our Akāŝa Gangā (Milky Way) and Lokākāŝa Map.

mass of our universe is merely $4 \%$ of the Universe. We have almost $72 \%$ in-visible dark energy and $23 \%$ invisible mass [4]. So how do we comprehend and represent this colossal universe?

\section{An Overview of Ancient Lokākāŝa (Schematic Arrangement of the Universe)}

In ancient Indian scriptures, the Universe is described in great detail by the Risisis, which has later been depicted through the maps also, known as Lokākāŝa map (Figure 3). Its Upper part, called Urdhva Loka has a height of 7 Rajjus ${ }^{\star}$ (Rajju is a unit of length). It consists of 8 types of heavens (Deva Loka) and Siddha ŝîlā $[5,6]$. The Lower Loka consists of 7 types of Hell (Narka land). The Middle Loka (Figure 4) is arranged around the mountain Meru. Its innermost circular land mass [6], termed as Jambudwipa, is surrounded by a circular ring of watermass, called LavańaSamudra. Such innumerable pairs of land-water masses go on forming the Middle Loka.

The first 2.5 land masses, called adhāidwīpas provide habitation for human-beings. Beyond these dwipas, mankind cannot trespass and survive. Our earth is supposed to be a part of Jambu-dwipa. It is located in the south and is termed as Bharat Kŝetra, adjoining Lavańa Samudra. Another interesting Kŝetra, called Mahāvideha Kŝetra is located from east to west, in the central part of Jambu-dwipa.

A normal question arises, as to why we are not able to locate them, even with our latest gadgets?

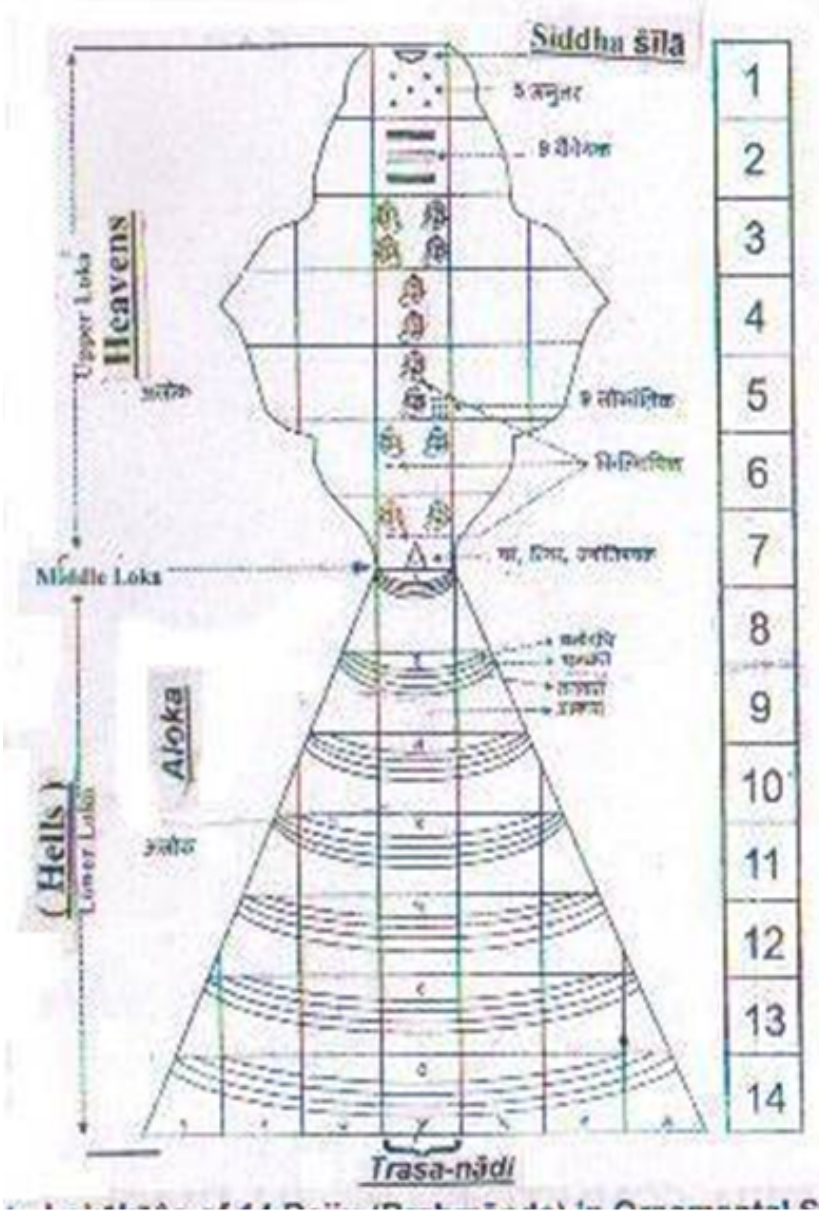

Figure 3: Lokākāŝa of 14 Rajju (Brahmānda) in Ornamental Style.

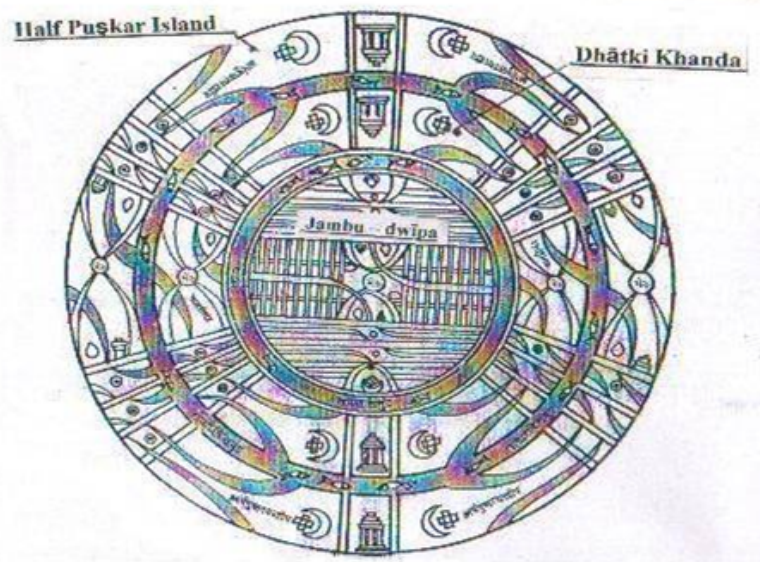

Figure 4: Middle Loka as Circular Pairs of Land and Water. 


\section{Possible Reasons}

At present, we are not at all in a comfortable position to co-relate the map of Geography and cosmology with that of ancient Lokākâsa. One should ponder critically at one point that this problem of mismatch was non-existent during the period of Mahaveera, although both of these maps were in vogue at that time.

One of the reasons could be that we have probably forgotten the exact method to read such map of Lokākāŝa over the long period of 2500 years. Let us try to re-search it for its proper interpretation, so that its hidden treasure could be deciphered. First, consider the total available contents of the Universe, in terms of living and non-living things.

\section{Possible Total Contents of the Universe}

The contents of the universe are of two types, called sentient and non- sentient matter. They are found in following categories, states and phases:

\section{Different states of non-living matter and its possible phases}

As per modern experimental data, matter can have 7 different states viz. Solid, Liquid, Gas, Plasma, Einstein-Bose, Derek-Fermion condensates and Sphatik (transparent) state. The last 3 states have so far been created in Labs only.

The first two states of matter are normally available on the surface of the planets in gross forms of Plains, Mountains, Rivers and Oceans.

They may or may not be surrounded by layers of $3^{\text {rd }}$ or higher states of matter.

\section{Phases of solid matter}

On increasing pressure and Temperature, matter can also change its phases, i.e. can transform itself from solid to liquid phase. If the pressure on a compressed matter continues to increase, its temperature would also go on increasing. For example, if we go farther below the crust of our earth (Figure 5), the solid material would first liquefy and as the depth increases, it would cross its sub critical, critical conditions and would finally reach super critical conditions. Accordingly, the internal structure of earth can be classified in 7 categories.

1. Warm solid

2. Hot paste

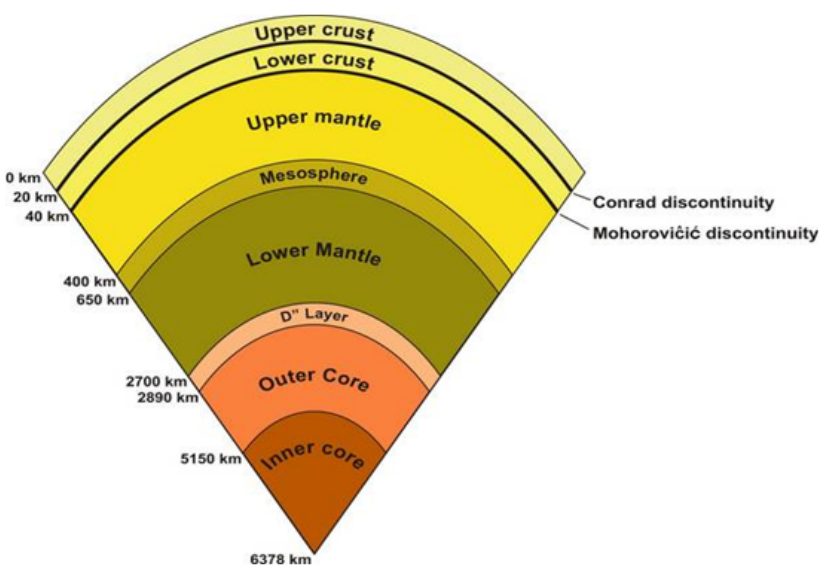

Figure 5: Different states of material at different depths inside our Earth.

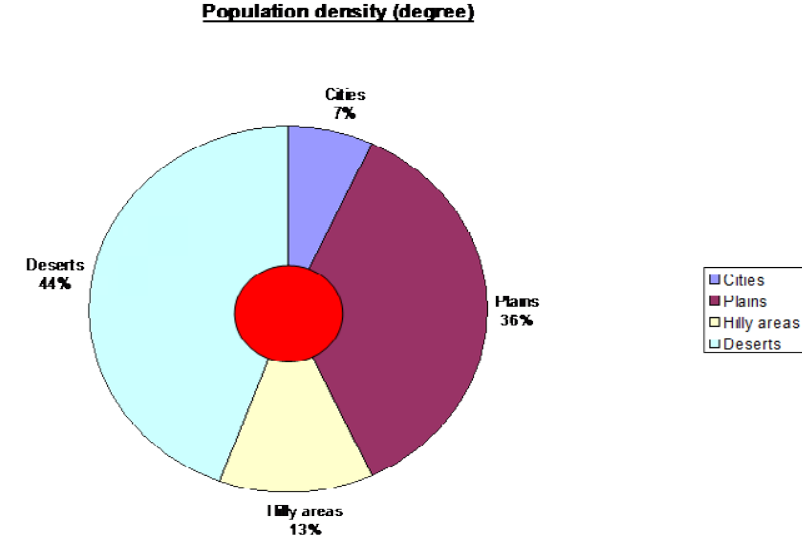

Figure 6: Pie-Chart for distribution of population density

3. Hot molten liquid

4. Super-hot molten mass

5. Cold paste/solid

6. Colder solid

7. Coldest dense solid

\section{States of living-beings}

Organic living-beings, called Gross bodies (Audarika Body ${ }^{1}$ ), (Mobile and immobile ones, having 1 to 5 senses). It includes human, animal and plant kingdom.

Non-organic living-beings (also possess Gross bodies, like water etc.). They are immobile and single sensed

Protean bodied $\left(\right.$ Vaikriya body ${ }^{2}$ ) living-beings, called Infernal beings. ( 5 sensed)

Highly energetic Protean bodied living-beings, called denizens of Heaven. (5 sensed).

\section{Methods to Present Data or To Construct a Cosmological Map}

a) The best way to present such huge statistical data of the Universe is through statistical Pictographs and Charts, like pie-charts, Bar-carts and Ring-charts

Example: One can statistically represent human population density distribution on the earth in a chart form like the Pie chart (Figure 6), or Quantity of different states of matter available in the Universe in Bar chart (Figure 7) or Bank advances under different heads in Ring-charts (Figure 8).

Thus the non-living and the living matter and its distribution in the Universe can be mathematically arranged systematically

Gross Body: It consists of gross material aggregates belonging to the audarikavargana (a group of material aggregates, which can be perceived through sense organs). In the mobile organisms, the constituent matter is in the form of flesh, bones, blood, skin etc. In the immobile beings, such as earth, water etc.; it is made of the inorganic and organic stuff.

${ }^{2}$ Protean Body: It consists of subtle material aggregates (may, at times, remain invisible), which can be made to undergo changes in its form at will. It can vanish like Camphor and join itself together back like drops of Mercury. This type of flexible body can be obtained by birth or through special techniques. 


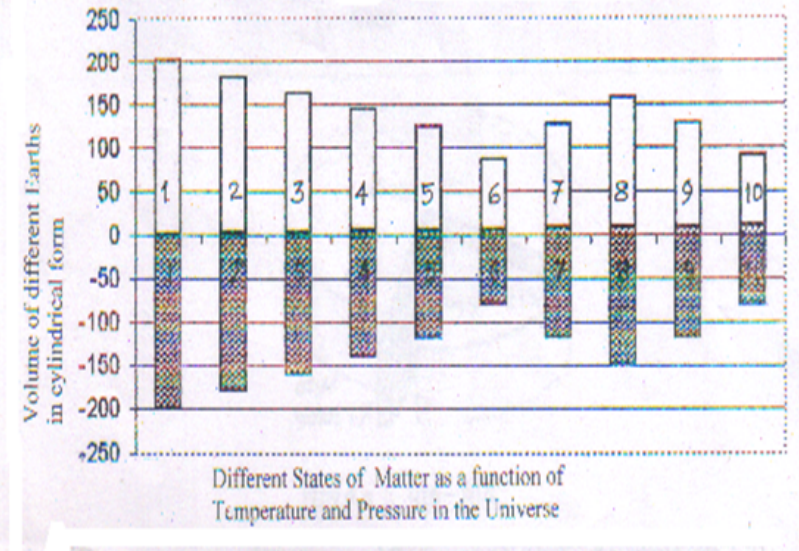

Figure 7: Different phases and states of matter in the Universe, presented as Bars around an Axis.

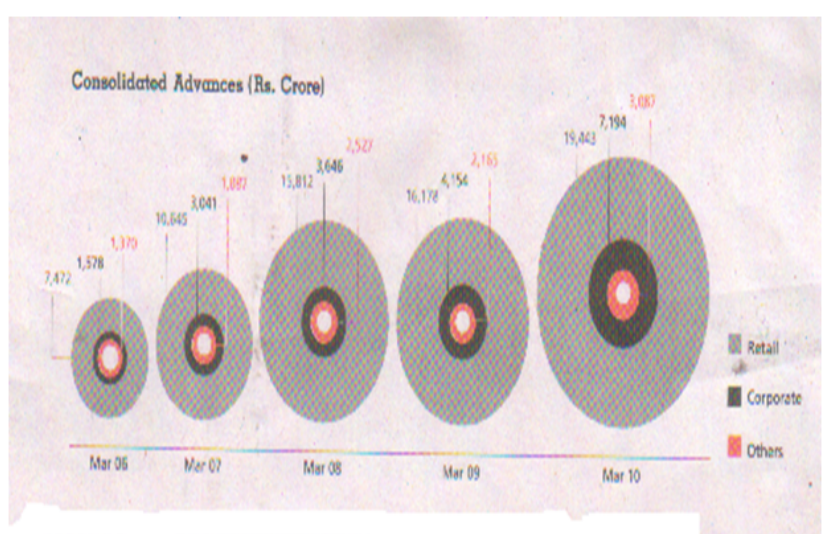

Figure 8: Ring-charts to depict Bank advances to different entities.

and represented symmetrically, as collective aggregates, for easy understanding for a layman, in form of Bars (lower and upper loka) and Rings (middle loka).

b) Before we try to re-look and rethink about these two types of maps, let us do one exercise.

Suppose we are asked to show distribution of earth population density, in steps like, 1-100, 100-1000, 1001-10000 persons/sq. km etc. All these types of similar density areas are clubbed together and then represented by a chart called pie-chart (Figure 6). The representation of the statistical data, at a glance, by a pictogram, like pie, bar or ringchart, is a standard mathematical method. Such charts have some special features, which must be kept in mind, while using them.

\section{Relationship between Living-Beings and Non-Living Matter}

A broad basis of arrangement of contents of the universe could be the following criteria:

\section{As per type of substances}

Categorizing all the materials as per their type and clubbing them together category-wise. These are then shown in form of statistical charts.

\section{As per type of living-beings}

Generally, one particular type or a group of 2-3 types of matter support a particular type of living-being. If two different types of living-beings are supported on the same type of matter, then they are segregated and depicted separately as per the type of Living-Beings.

It is found that all the human beings can be arranged in a relatively small area of two and a half Islands (dwipas) only.

It is obvious that such mammoth data can be made available only by super human-beings. They are called Risis. Similarly, this extraordinary data about such a huge universe could not have been presented in understandable form by an ordinary human-being, some 3 thousand years ago. I seems that only a super human-being could have generated such a huge database and thought of using special statistical charts to exhibit the living and non-living contents of the universe in simple and plausible manner for ordinary lay man.

\section{Actual Arrangement of All the Known Contents- Animate and Inanimate With Respect To Their States, In a Fine Tuned Style in Lokākāŝa Map (A Pictograph)}

All the matter, including subliminal (Protean) substance and all the living-beings have been clubbed together, categorized and then presented in the form of statistical charts.

\section{Non-living matter (pudgaladravya)}

If all the non-living matter of every phase available in the universe (Loka including $2 \frac{1}{2}$ dwipas) is clubbed together and is arranged in the following manner:

First 3 phases: Land and Water (with gas) in form of rings of land and water mass. It forms the Middle Loka.

The 7 phases of first 2 types of substances, as found inside the earth, have been depicted in form of Bar/strips -charts. They are called Lower Loka in the pictograph.

The last 3 phases (as created in labs), in form of bars and strips, would form the Upper-Loka of the pictograph.

After obtaining the shape of universe by stacking one phase of matter over the other, we look into the arrangement of its living-beings.

\section{Living-beings}

The various types of Living-beings are supported by different but specific types of physical substances. For example, the bodies of humanbeings or animal kingdom cannot be supported by the substances of lower and upper loka.

Lower loka has very special levels of temperature and pressure working on the first 2 types of substances.

All the data about the gross-bodied living-beings has been beautifully arranged in form of Ring-charts, one ring engulfing the other one in the middle Loka. As pairs of Land (continents) and water mass (Oceans), the contents of the whole middle loka have been arranged with the following discipline (rules):

\section{Condition 1}

Each state of matter supports, in a befitting manner, a particular type of Body (Kāyā) of living-being, so that each type of mobile livingbeing can also be clubbed together for that state of matter. 


\section{Condition 2}

In terms of Space, the Rings of alternate land-water mass depict areas in such a manner that the area of a ring doubles itself from its preceding ring area. The total area of middle loka is equal to that of a circular disc of 1 Rajju (R) diameter. (Rajju is an ancient unit of length).

In middle loka, the first 3 states of matter, have been arranged, which have got suitability/capability to support Living-beings having gross bodies "(Audarika-Life").

\section{The protean form of life}

The matter of Upper and Lower Loka supports mobile creatures of specific type of protean substance (Vaikriya Pudgalas). Living-Bodies of high energy (ŝbh) VaikriyaPudgalas are arranged in Upper Loka and those ofpoor quality Vaikriya Pudgalas are arranged in Lower Loka. The total areas of every specific phase of matter, occupied by such different creatures, are identified, measured and displayed in the above mentioned Bar-Charts. As for example, 5th phase of matter may support only Vaikriya bodies, i.e, bodies of a particular type of Denizens (celestial-beings). Accordingly, it is shown as a strip in the bar-chart.

The plasma-phase of matter and the plasma supported livingbeings are arranged in the Luminal (Jyotishka) kingdom, placed just above the middle loka, but below the upper loka, as its part only. It consists of luminal living beings. The protean-bodied living-beings, residing in eternally available plasma bodied vehicles, are distinctively different from other types of living-beings. The plasma vehicles are also different from the shining planets or satellites.

\section{Deductions and Inferences from the Statistical Map (Chart)}

Once the classification, categorization and arrangement of various types of living and non-living contents and its different phases, states and interdependence with respect to Time have been understood and grasped properly, it would become easier to interpret and explain the pictograph, called Lokākāŝa Map.

\section{While reading the statistical chart of the universe, following conditions should be kept in mind}

Any bar or ring is a symbolic representation of the similar states or types of living or non-living matter. Individually it might be scattered throughout the length and depth of the universe. It is clubbed together and its sum total is represented as a Bar or Ring on a certain scale.

The mutual distances of various objects vanish in such charts, because they are all clubbed together.

As per science also, different types and phases of living and non-living matter, are scattered all over this vast Universe. It would be impossible to show and understand their locations through any prevalent geographical maps. The Risis have, by use of these decorative looking pictographs, made us understand the contents of this vast Universe in a simple and quantitative language. This symmetrical showpiece gives, at a glance, important information about the distribution of all the living and non-living matter of the Universe. It takes us far beyond the present level of our knowledge and explains many hitherto unknown features in a plausible manner.

\section{Some of the Important Inferences and Discussion}

Human civilizations, similar to ours, exist on several planets in the vast expanse of the Universe. Some of the extra-terrestrial civilizations are spiritually more advanced than ours. The human habitats, shown on the central dwipa, called the Jambudwipa, may be located (i.e. made up of planets) in our Galaxy only.

Sub-human life form exists on innumerable planets in the universe.

Protean form of life (Denizens) may be a reality. Its low-energy version should be available deep inside the cosmological objects, including our planet earth. Its highly developed version of life form should exist, around all the luminous as well as the non-luminous objects of the universe, wherever its supporting matter exists.

This statistical chart of the universe gives data about the total size, area and volume, as occupied by the different types of living and non-living matter. It should not be confused with the traditional Geographical and astrological map, as was being done till now.

It enables us to take the modern scientists in a realm beyond the present day knowledge and explain its unknown features in a plausible manner.

Some of the important revelations are as follows:-

The Living-beings are of 4 categories. Out of it, 2 types have bodies made up of protean matter. The Protean-bodied form of life (Denizens) is of 2 types. Contact with them is possible, only if we can investigate and understand the properties of this special material.

It also suggests the existence of some other forms of physical bodies of living-beings. Recent research on water has, at least, proved the existence of inorganic form of life [7].

\section{References}

1. Oxford School Atlas (2010) Oxford Uni Press.

2. Gurevich LE, Chernin AD (1987)The Magic of Galaxies and Stars. Mir Publication, Moscow, Russia.

3. Mahanti S (2009) Khagol Vigyanki Utpattiaur Vikas. Avishkar.

4. Tiwāri VM (2010) AdřsyaUrjā: Brahmāndakā Anayatama Rahasya. Ăvişkāra.

5. Amolaka R (1968) Jaina Tattva Prakāsa, Amolaka Jaina Granthālaya.

6. Sāgaraji P (2000) Jaina Tattva Vidyā. Karnānuyoga, Bhārtiya Gyānapitha.

7. Jain J (2012) Science of Dhovana Water, Samyaggyan Pracharak Mandal Jaipur, India. 